\title{
The variation of finger tremor with age in man
}

\author{
AT BIRMINGHAM, HJ WHARRAD, EJ WILLIAMS* \\ From the Department of Physiology and Pharmacology, Medical School, Queen's Medical Centre, and \\ Department of Mechanical Engineering, ${ }^{*}$ University of Nottingham, Nottingham, UK
}

SUMMARY The variation of the amplitude and frequency of finger tremor was studied in 190 subjects ranging in age from 7 to 77 years. Tremor was measured in various postures with an accelerometer and a transduced signal was analysed by Fourier analysis. The variation of tremor frequency and amplitude with age depended upon the posture adopted for measurement and in certain postures some of the variation was related to changes in stature with age.

The variation in tremor between individuals has prompted surveys of the way in which the variation is related to age. Marshall and Walsh' measured tremor in children and adults using a double-diode accelerometer at various sites of the body and concluded that generally children showed lower dominant frequency than adults: Marshall ${ }^{2-3}$ used visual analysis of the waveform from an accelerometer, held in the hand with the arms outstretched in front of the body, to estimate tremor frequency. Based on records from over 600 subjects, randing in age from 2-96 years, he concluded that dominant frequency increased from $5-6 \mathrm{~Hz}$ in children to $8-12 \mathrm{~Hz}$ in adults with a gradual decrease after 40 years of age to $6-7 \mathrm{~Hz}$ at the age of 70 . Buskirk and Fink ${ }^{4}$ using optical methods of measurement and visual analysis found a similar trend in 140 subjects.

Marsden, Meadows, Lange and Watson ${ }^{5}$ used spectral analysis of recordings from an accelerometer on the index finger in 88 subjects from 3 to 85 years of age and found no difference in dominant frequency between children and adults; frequencies were in the range of 8-9 Hz, but over the age of 60 dominant frequency decreased to $7 \cdot 7 \mathrm{~Hz}$.

One study has shown a higher dominant frequency in children than in adults, ${ }^{6}$ but the methods of analysis were subjective and measurement techniques less sensitive than those used in the other studies quoted.

There is no close agreement between the few tremor studies on age variation so far reported. The measurement techniques, the postures adopted dur-

Address for reprint requests: Prof AT Birmingham, Department of Physiology and Pharmacology, Medical School, Queen's Medical Centre, Nottingham, NG7 2UH, UK

Received 9 November 1984. Accepted 5 December 1984 ing measurement and the methods of analysis varied widely, which may account for the disagreement. We now report a survey of finger tremor using spectral analysis of accelerometer recordings in three different postures to try to resolve some of the disagreement.

\section{Methods}

\section{Subjects}

The subjects were randomly selected from the following populations: (1) 7-11 years olds from a local junior school; (2) 11-18 years olds from a local comprehensive school; (3) 19-64 years olds from the students and staff at the Medical school (4) over 65-year-old males attending the Medical School for other physiological measurements; (5) over 65 -year-old females attending a local keep fit class. Table 1 shows the age group classifications with the mean age, height and weight for each group. Of the 190 subjects 102 were female and 88 were male; 10 subjects were left handed.

\section{Tremor measurement}

Measurements of finger tremor of both hands were made using a small accelerometer (mass 13g) (Bruel and Kjaer type 4367 ) attached by a "Perspex" ring (mass $2 \mathrm{~g}$ ) to the terminal phalanx of the middle finger. Recordings were made sequentially in three different positions ${ }^{7}(1)$ with the forearm supported and the hand relaxed ("rest" tremor), (2) with the arm and hand outstretched ("postural" tremor), and (3) with the forearm and hand supported and the middle finger exerting an upward force of $1 \mathrm{~N}$ against the spring of a strain-gauge transducer (Grass Instruments) ("work" tremor).

All measurements were made with the subject seated comfortably in a specially-reinforced chair in a quiet room. In situations in which recordings could not be made in the laboratory, equipment was set up in a quiet room where no external distractions or vibrations were evident. A background vibration recording was taken prior to the day's recording session and compared with that taken in the 
Table 1 Mean age, age range, mean height and mean weight of subjects making up the 9 age groups. The number of subjects comprising each group is also indicated

\begin{tabular}{|c|c|c|c|c|c|c|c|c|}
\hline \multirow{2}{*}{$\begin{array}{l}\text { Age group } \\
(y r)\end{array}$} & \multirow{2}{*}{$\begin{array}{l}\text { Mean age } \\
(y r)\end{array}$} & \multirow{2}{*}{$\begin{array}{l}\text { Age range } \\
(y r)\end{array}$} & \multirow{2}{*}{$\begin{array}{l}\text { Mean height } \\
(+1 S D)(m)\end{array}$} & \multirow{2}{*}{$\begin{array}{c}\text { Mean weight } \\
\left(^{+} \text {ISD) (kg) }\right.\end{array}$} & \multicolumn{3}{|l|}{ Subjects } & \multirow{2}{*}{$\begin{array}{l}\text { Number } \\
\text { left handed }\end{array}$} \\
\hline & & & & & number & male & female & \\
\hline $7-9$ & $8 \cdot 3$ & $7 \cdot 3-9 \cdot 3$ & $\begin{array}{l}1 \cdot 3 \\
(0 \cdot 1)\end{array}$ & $\begin{array}{l}28 \cdot 8 \\
(5 \cdot 9)\end{array}$ & 22 & 7 & 15 & 2 \\
\hline $9-11$ & $10 \cdot 7$ & $9 \cdot 3-11 \cdot 8$ & $\begin{array}{l}1.4 \\
(0 \cdot 1)\end{array}$ & $\begin{array}{l}31 \cdot 2 \\
(4 \cdot 4)\end{array}$ & 28 & 11 & 17 & 2 \\
\hline $11-13$ & $12 \cdot 9$ & $11 \cdot 9-13.8$ & $\begin{array}{l}1 \cdot 6 \\
(0 \cdot 1)\end{array}$ & $\begin{array}{l}43.4 \\
(9 \cdot 6)\end{array}$ & 24 & 10 & 14 & 1 \\
\hline $13-15$ & $14 \cdot 9$ & $13.9-15 \cdot 8$ & $\begin{array}{l}1 \cdot 8 \\
(0 \cdot 1)\end{array}$ & $\begin{array}{l}51 \cdot 3 \\
(7 \cdot 9)\end{array}$ & 22 & 12 & 10 & 2 \\
\hline $16-18$ & $17 \cdot 4$ & $16 \cdot 8-17 \cdot 9$ & $\begin{array}{l}1 \cdot 8 \\
(0 \cdot 2)\end{array}$ & $\begin{array}{l}62.0 \\
(11.0)\end{array}$ & 13 & 7 & 6 & 0 \\
\hline $19-29$ & $24 \cdot 7$ & $21 \cdot 0-28 \cdot 8$ & $\begin{array}{l}(0.2) \\
1 \cdot 7 \\
(0 \cdot 1)\end{array}$ & $\begin{array}{l}64 \cdot 0 \\
(9 \cdot 1)\end{array}$ & 20 & 10 & 10 & 0 \\
\hline $30-49$ & $35 \cdot 5$ & $30 \cdot 0-43 \cdot 5$ & $\begin{array}{l}1.7 \\
(0.1)\end{array}$ & $\begin{array}{l}64 \cdot 5 \\
(10 \cdot 0)\end{array}$ & 20 & 10 & 10 & 2 \\
\hline $50-64$ & $56 \cdot 7$ & $50 \cdot 4-63 \cdot 5$ & $\begin{array}{l}1.7 \\
(0 \cdot 1)\end{array}$ & $\begin{array}{l}69 \cdot 3 \\
(11 \cdot 8)\end{array}$ & 20 & 10 & 10 & 0 \\
\hline $65+$ & $69 \cdot 0$ & $65 \cdot 3-79 \cdot 0$ & $\begin{array}{l}1 \cdot 6 \\
(0 \cdot 1)\end{array}$ & $\begin{array}{l}63.6 \\
(13.7)\end{array}$ & 21 & 11 & 10 & 1 \\
\hline
\end{tabular}

laboratory and shown not to be different. Measurements were made for one minute in each of the three positions for each hand and recorded via a charge amplifier (Bruel and Kjaer type 2635) onto a Racal FM taperecorder for further analysis.

\section{Tremor analysis}

Frequency analysis of the tremor waveform, filtered to remove frequencies above $50 \mathrm{~Hz}$ to prevent alias contamination, was carried out using a Hewlett-Packard 3582A spectrum analyser, remotely programmed with a type 9825A desk-top calculator in conjunction with a type 7225A graph plotter and double disc drive (HP 9885S \& HP 9885M). Five-second epochs of the analogue signal were digitised and subjected to Fourier analysis, the frequency spectra from eight sequential epochs were averaged to yield from each subject a mean frequency spectrum covering the range 0.4 to $51.2 \mathrm{~Hz}$ in $0.2 \mathrm{~Hz}$ intervals. A Hann passband was used to minimise leakage. From the frequency spectra the root mean square (rms) of tremor amplitude was calculated.

For identification of the dominant frequency, each mean frequency spectrum was smoothed by the method of "smoothing by threes": for each spectral point, the computer summed half its amplitude value with one quarter of the amplitude value of each of the two adjacent points. This process was repeated 23 times. From the smoothed spectrum the dominant peak was identified as the peak of greatest amplitude and the frequency of this dominant peak was determined.

\section{Other measurements}

The height and weight of each subject were measured prior to tremor measurement. Where appropriate a questionnaire was completed to allow factors such as recent caffeine and alcohol intake, occupation and normal physical activity to be established. Each subject's customary caffeine-containing beverage intake was allowed but recordings were not made within 12 hours of any alcohol consumption, nor within 24 hours of unaccustomed physical exertion.

\section{Statistical analysis}

Rms acceleration and dominant frequency for the youngest age group were compared with other age groups using unpaired $t$ tests. Children and adults were also considered separately and inspection of scattergrams of age versus amplitude and frequency suggested that linear trends with years adequately described the data. Therefore linear regression analysis was performed for tremor amplitude and freqeuncy against age for each posture and for dominant and non-dominant hands and the corresponding correlation coefficients were calculated.

The relative influence of age, height and weight contributing to the variance of the tremor data was assessed using multiple linear regression techniques.

\section{Results}

The mean age, age range, mean height and mean weight of subjects are shown in table 1 . The results for the children were segregated into the "school years" in which they were measured (analysis in strict age classes gave similar results).

The frequency spectra for the individual subjects within each age group were combined to produce a mean frequency spectrum for each of the nine age groups covering the age range from 7 years to over 65 years. Examples of these mean frequency spectra, smoothed to increase clarity, are shown for selected age groups for rest, postural and work tremor in fig $1 \mathrm{a}, \mathrm{b}$ and $\mathrm{c}$ for the dominant and the non-dominant hands. The two basic quantitative parameters, rms accleration as a measure of amplitude and the frequency of the dominant peak were derived from the spectra of each individual in each 
(a)

Children

Adults
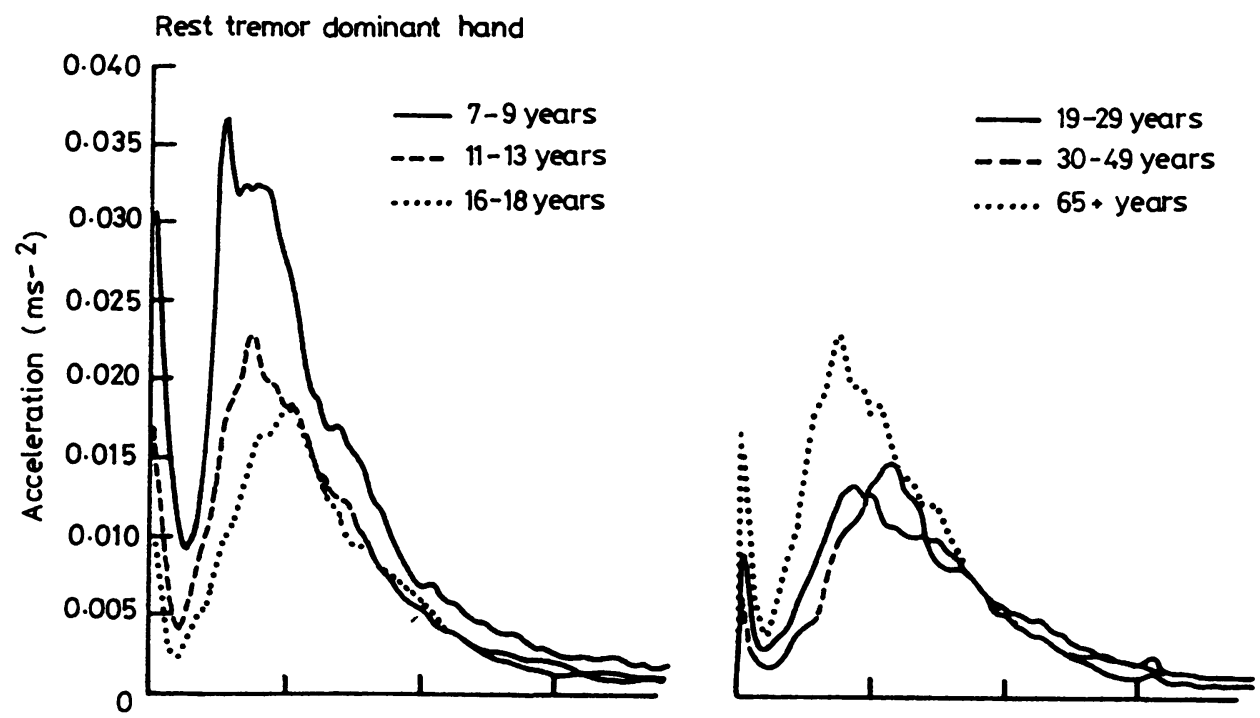

Rest tremor non-dominant hand
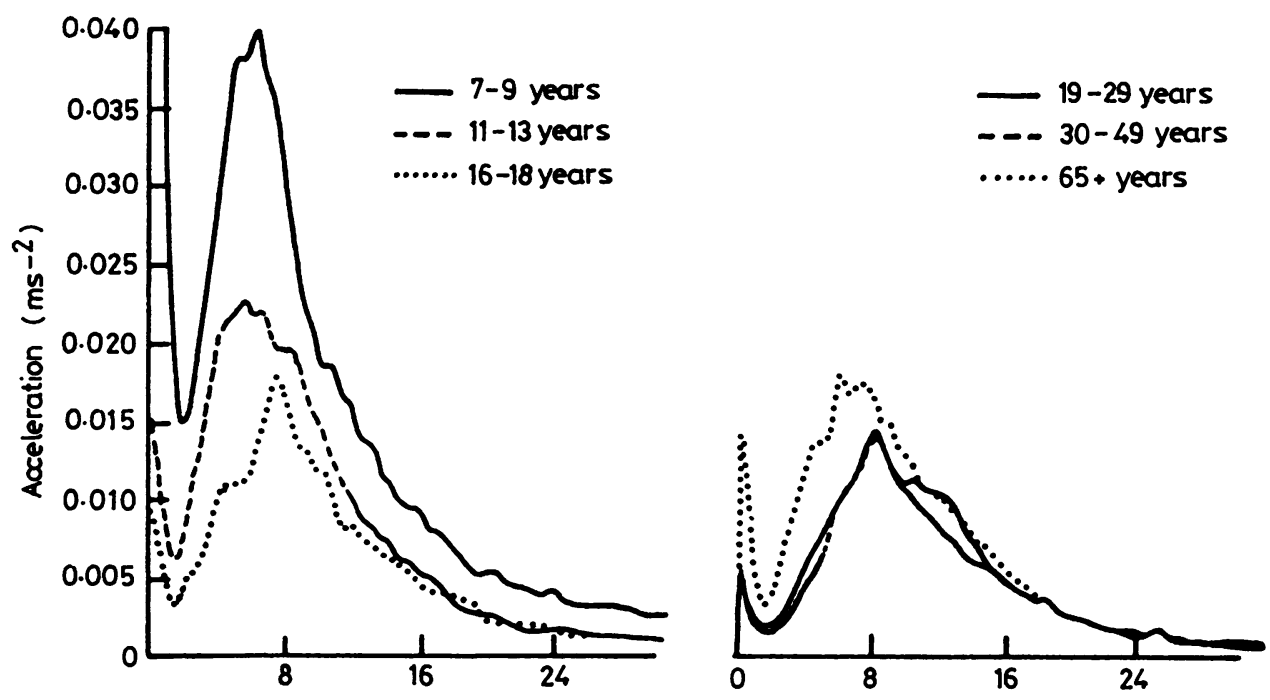

Frequency $(\mathrm{Hz})$

Fig 1 The mean frequency spectra (smoothed) for selected age groups for (a) rest, (b) postural and (c) work tremor. Spectra for the dominant hands are shown in the upper figures and for the non-dominant hand in the lower figures. Ordinates: acceleration $\left(\mathrm{ms}^{-2}\right)$, abscissae: frequency $(\mathrm{Hz})$ 

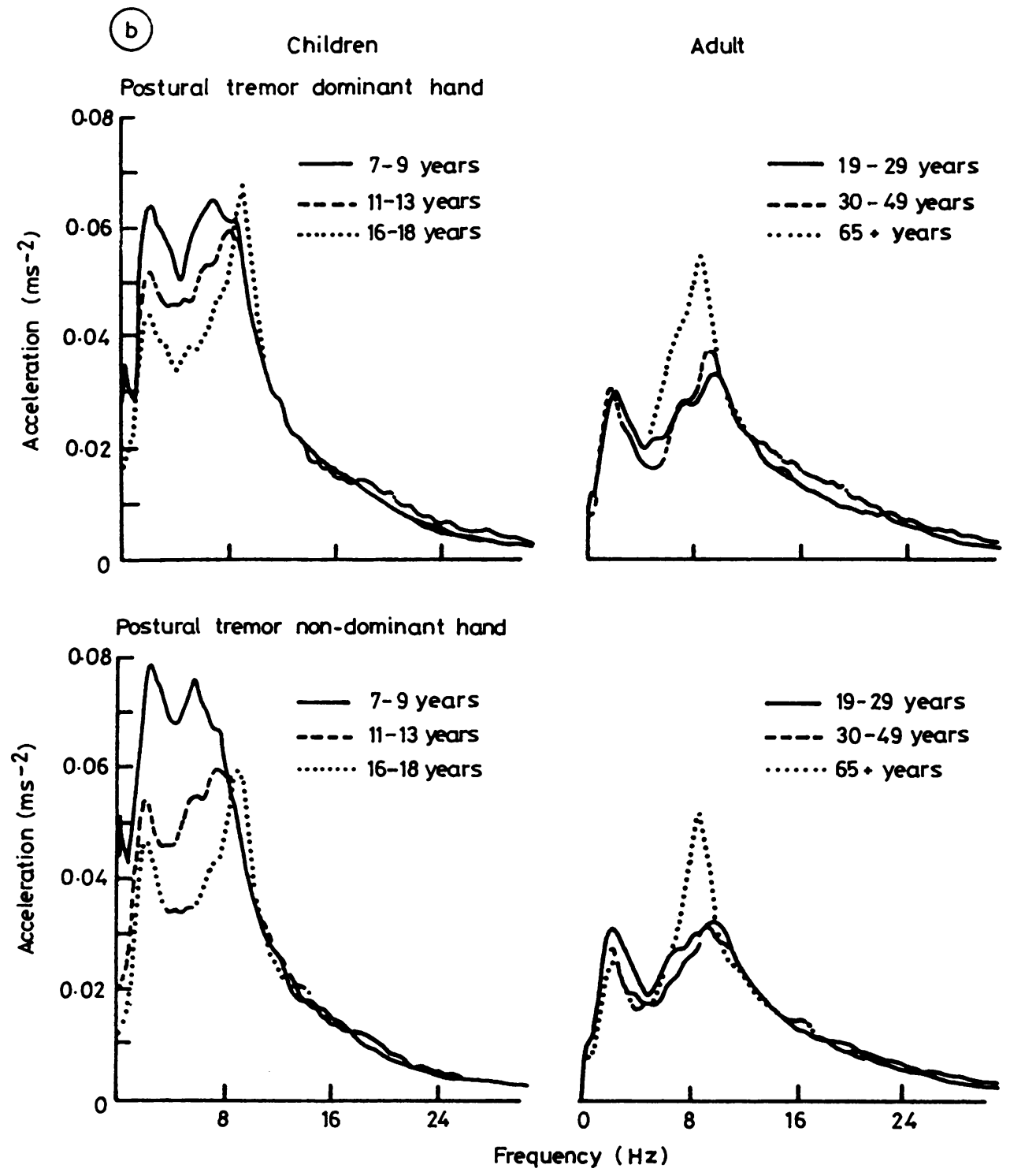

age group and the means of these values are displayed in fig $2 a$ and $b$.

For rest tremor the rms amplitude was greatest in the youngest subjects and declined with increasing age to reach its lowest levels in early and middle adult life, then rose again in the older subjects. With the arms outstretched (postural tremor) finger tremor declined with age, slightly to rise again over the age of 65 years. When the tremor was measured whilst the finger exerted a standardised extensor thrust (work tremor) the adult groups had smaller rms amplitudes than the children, with the oldest adults not showing such a pronounced tendency to rise as in the other measurement postures.

A shift in the frequency of the dominant peak emerged with increasing age. Generally speaking, for rest tremor and postural tremor, frequency rose throughout childhood to reach its highest levels in 

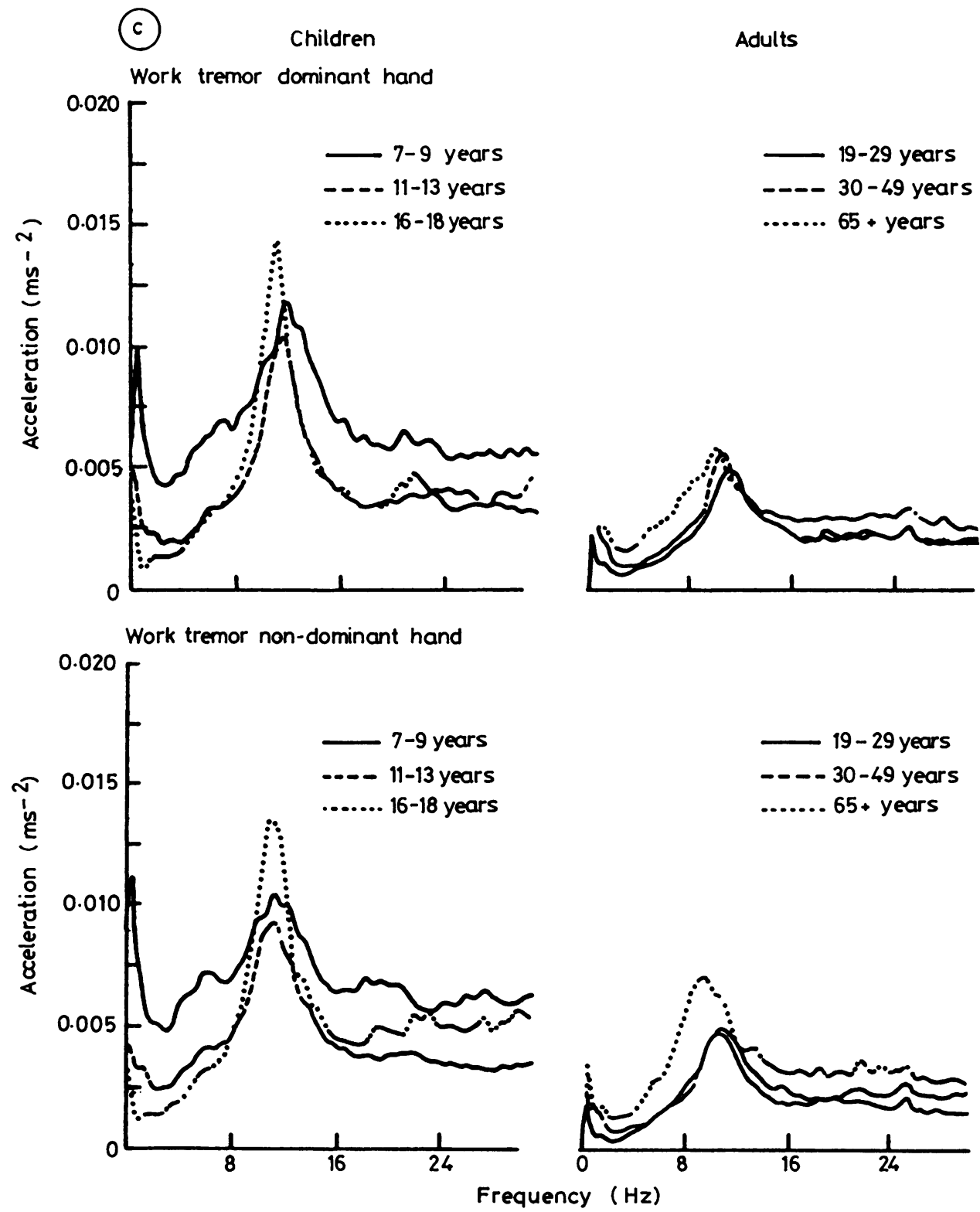

adult life with a tendency to fall again in later life. The trend was quite different for work tremor; children had a higher dominant frequency than adults who showed a gradual decline in frequency with advancing years, the lowest frequency being shown by the oldest group of subjects.
Statistical comparisons

For analysis of the statistical significance of the differences outlined above, the values for the youngest group of subjects were used as the reference point. The pattern of statistically significant differences (Student's $t$ test for unpaired samples) is also shown 
(a) Rest

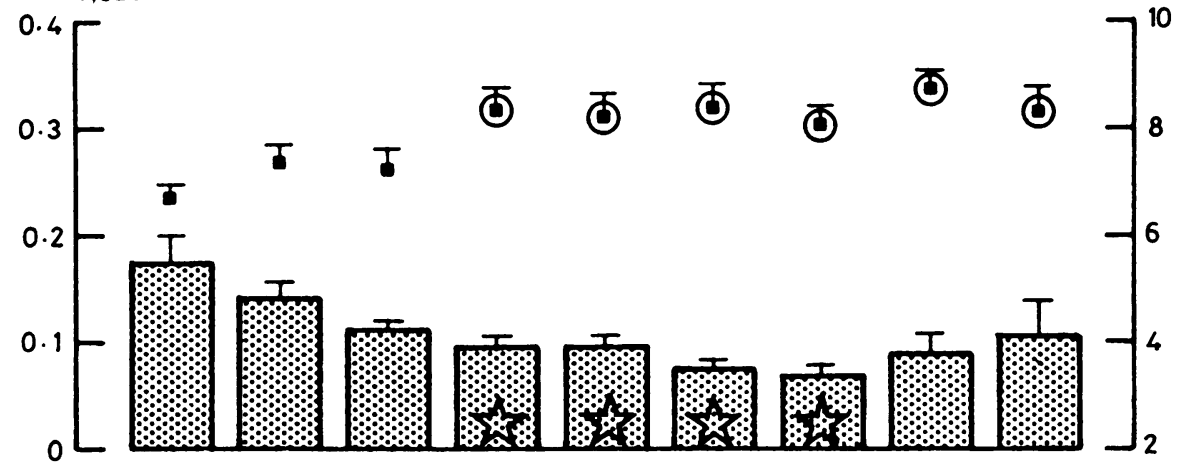

Dominant hand

Postural
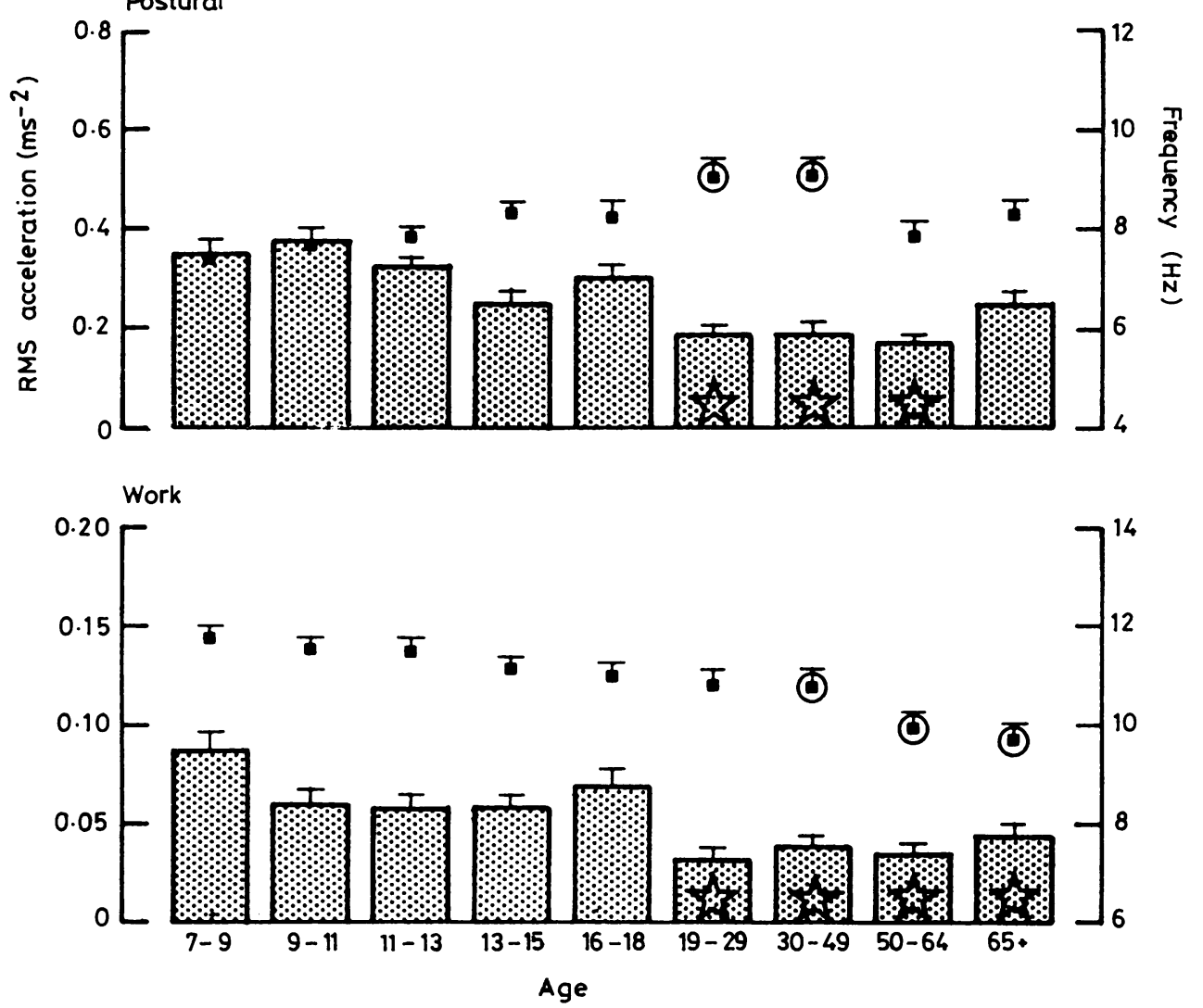

Fig. 2 Mean $\left({ }^{+} S E\right)$ rms acceleration for the 9 age groups ranging from 7 to 79 years shown as shaded bars for the (a) dominant and (b) non-dominant hands: rest tremor, postural tremor and work tremor. Statistically significant differences are shown as stars $(<p 0.05)$ and are for the comparison with the 7-9 year age group (Students $t$ test for unpaired samples). Mean $(+S E)$ dominant frequencies are shown as black squares ( $\square$ with statistically significant differences $(p<0.05)$ from the 7-9 year group being shown as circles $(O)$. Lefi hand ordinate: acceleration $\left(\mathrm{ms}^{-2}\right)$, right hand ordinate: frequency $(\mathrm{Hz})$, abscissa: age groups $(y r)$ 

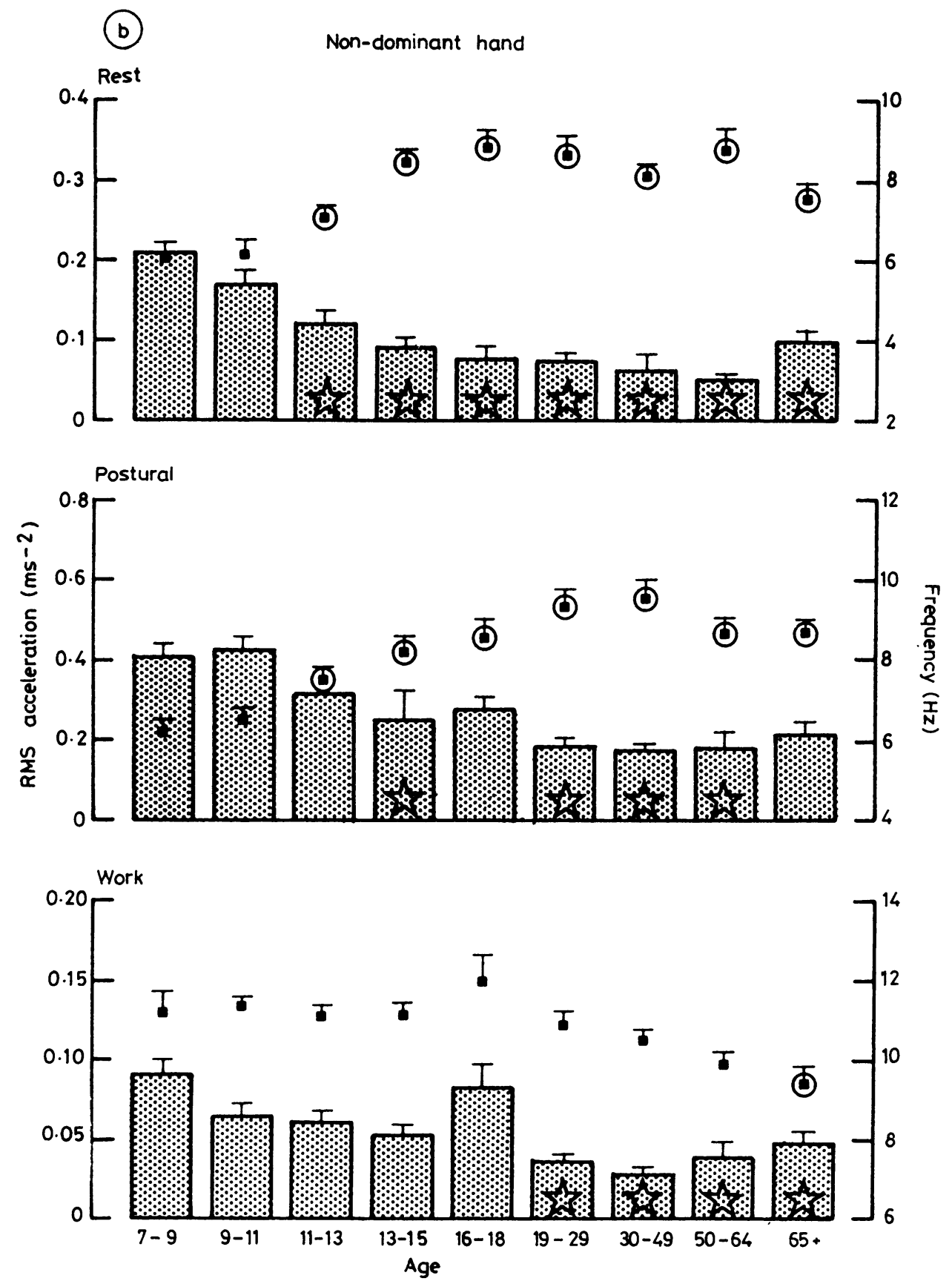

in fig 2a and b. It can be summarised that for rest tremor, amplitude in the dominant hand was significantly lower in adolescence and early adult life than in childhood; for the non-dominant hand the statistically significant difference was sustained to

later life. The range of years over which older subjects had significantly less-pronounced tremor than the young children was smaller for postural tremor for both hands. Work tremor uncovered statistically significantly lower amplitudes of tremor in both 
Table 2 Correlation coefficients for the regression lines rms acceleration and frequency on age for children and adults and for each measurement posture. The statistical significance of each correlation is shown

\begin{tabular}{|c|c|c|c|c|c|}
\hline Measurement posture & Hand & $\begin{array}{l}\text { Acceleration } \\
\text { Children }\end{array}$ & Adults & $\begin{array}{l}\text { Frequency } \\
\text { Children }\end{array}$ & Adults \\
\hline \multirow[t]{2}{*}{ Rest } & Dominant & $-0.338 \ddagger$ & 0.182 & $0 \cdot 260^{\dagger}$ & $0 \cdot 131$ \\
\hline & Non Dominant & $-0.486 \ddagger$ & $\begin{array}{l}\text { NS } \\
0.191 \\
\text { NS }\end{array}$ & $0.481 \ddagger$ & $\begin{array}{l}\text { NS } \\
-0 \cdot 120 \\
\text { NS }\end{array}$ \\
\hline \multirow[t]{2}{*}{ Postural } & Dominant & $-0.237^{*}$ & $0 \cdot 114$ & $0 \cdot 228^{*}$ & $-0 \cdot 184$ \\
\hline & Non Dominant & $-0.463 \ddagger$ & $\begin{array}{l}\text { No } \\
\text { NS }\end{array}$ & $0 \cdot 493 \ddagger$ & $-0.262^{*}$ \\
\hline \multirow[t]{2}{*}{ Work } & & $\begin{array}{l}-0 \cdot 167 \\
\text { NS }\end{array}$ & $\begin{array}{l}0 \cdot 069 \\
\text { NS }\end{array}$ & $-0 \cdot 209^{*}$ & $-0.370 \ddagger$ \\
\hline & Non Dominant & $\begin{array}{l}-0 \cdot 111 \\
\text { NS }\end{array}$ & $\begin{array}{l}0 \cdot 191 \\
\text { NS }\end{array}$ & $\mathrm{NS}^{0.039}$ & $-0 \cdot 397 \ddagger$ \\
\hline
\end{tabular}

NS, not significant: ${ }^{*} p<0 \cdot 05 ; \nmid p<0 \cdot 01 ; \ddagger p<0 \cdot 001$

hands in all the adult groups compared with that of the youngest children. The dominant frequency of the tremor was significantly higher in rest tremor after the ages of 11-13 (dominant hand) or 9-11 (non-dominant hand) had been reached and remained higher in the older age groups. This was also true of postural tremor (non-dominant hand) but the fall in frequency in later life on the dominant side brought the frequency into the same range as that of the youngest children. For work tremor the gradual decline in frequency reached statistically significant proportions on the non-dominant side in the oldest subjects but at an earlier stage (from the 30-49 age group) on the dominant side.
For further analysis of the changes outlined above, the children ( $7-17$ years, $n=109$ ) and adults (19-77 years, $n=81$ ) were considered separately. Linear regression analysis was performed for tremor amplitude and for dominant frequency against age for each posture and for dominant and nondominant hands. Correlation coefficients for these regressions are listed in table 2 . The linear regression analysis confirmed the trends seen in fig $2 \mathrm{a}$ and $b$, the salient features being that tremor amplitude declined with age in children for each measurement posture but the decline was significant only for rest and postural tremor $(\mathrm{r}=-0.237$ to $-0.486, \mathrm{p}<$ 0.05 or $p<0.001)$. The opposite trend was seen for

Table 3 Multiple linear regression coefficients for the regression of tremor amplitude and dominant frequency on age, height and weight

^ for each measurement posture. The statistical significance of the value of $R^{2}$ is shown: ${ }^{*} p<(1) \cdot(1) 5$;

$\left.{ }^{* *} p<0.01 ;{ }^{* * *} p<0.001\right)$.

\begin{tabular}{|c|c|c|c|c|c|c|c|c|c|c|c|}
\hline Measurement posture & Hand & $\begin{array}{l}\text { Children } \\
\text { Age }\end{array}$ & Height & Weight & Constant & $R^{2}$ & $\begin{array}{l}\text { Adults } \\
\text { Age }\end{array}$ & Height & Weight & Constant & $R^{2}$ \\
\hline $\begin{array}{l}\text { RMS acceleration } \\
\text { Rest }\end{array}$ & Dominant & $<-0.001$ & -0.159 & $<0.001$ & 0.395 & $\underset{* * *}{0 \cdot 15}$ & $<0.001$ & $0 \cdot 095$ & $<0.001$ & $-0 \cdot 151$ & $\begin{array}{l}0.09 \\
*\end{array}$ \\
\hline - & Non Dominant & -0.012 & $-0 \cdot 190$ & $0 \cdot 002$ & $0 \cdot 510$ & $0 \cdot 27$ & $<0.001$ & $-0 \cdot 020$ & $<-0.001$ & $0 \cdot 003$ & 0.11 \\
\hline \multirow{2}{*}{ Postural } & Dominant & $-0 \cdot 011$ & $0 \cdot 110$ & $-0 \cdot 002$ & $0 \cdot 355$ & $0 \cdot 06$ & $<0.001$ & $0 \cdot 285$ & $<0 \cdot 001$ & -0.393 & $0 \cdot 10$ \\
\hline & Non Dominant & -0.027 & $0 \cdot 161$ & $<-0.001$ & 0.478 & $\underset{* * *}{0 \cdot 24}$ & $<0.001$ & $0 \cdot 281$ & 0.002 & -0.433 & $0 \cdot 19$ \\
\hline Work & Dominant & -0.002 & -0.002 & $<0.001$ & $0 \cdot 111$ & $0 \cdot 04$ & $<0.001$ & -0.065 & $<0.001$ & $0 \cdot 113$ & $0 \cdot 04$ \\
\hline- & Non Dominant & -0.002 & $0 \cdot 067$ & -0.001 & $0 \cdot 040$ & 0.03 & $<0.001$ & -0.019 & $<0.001$ & 0.052 & $0 \cdot 02$ \\
\hline \multirow[t]{2}{*}{$\begin{array}{l}\text { Frequency } \\
\text {-Rest }\end{array}$} & Dominant & 0.031 & $0 \cdot 524$ & $0 \cdot 024$ & $5 \cdot 665$ & $\begin{array}{l}0.09 \\
* *\end{array}$ & -0.019 & $-5 \cdot 272$ & $0 \cdot 026$ & $16 \cdot 286$ & 0.05 \\
\hline & Non Dominant & $0 \cdot 184$ & $3 \cdot 155$ & -0.015 & $0 \cdot 985$ & $\begin{array}{l}0 \cdot 26 \\
* * *\end{array}$ & 0.010 & $-3 \cdot 789$ & $0 \cdot 013$ & $13 \cdot 625$ & $0 \cdot 05$ \\
\hline \multirow[t]{2}{*}{ Postural } & Dominant & $0 \cdot 076$ & -1.985 & $0 \cdot 030$ & $8 \cdot 782$ & $0 \cdot 07$ & -0.011 & $0 \cdot 862$ & $-0 \cdot 026$ & $9 \cdot 415$ & $0 \cdot 05$ \\
\hline & Non Dominant & $0 \cdot 322$ & $-2 \cdot 197$ & $0 \cdot 022$ & $5 \cdot 673$ & $\begin{array}{l}0 \cdot 28 \\
* * *\end{array}$ & $-0 \cdot 019$ & $0 \cdot 865$ & -0.023 & $10 \cdot 135$ & $0 \cdot 08$ \\
\hline Work & Dominant & 0.001 & -0.633 & -0.009 & $12 \cdot 966$ & $0 \cdot 06$ & -0.025 & 0.537 & -0.029 & $12 \cdot 601$ & $\begin{array}{l}0 \cdot 23 \\
* * *\end{array}$ \\
\hline x & Non Dominant & $0 \cdot 006$ & $1 \cdot 062$ & -0.011 & $10 \cdot 188$ & $0 \cdot 01$ & -0.032 & -1.672 & -0.017 & $15 \cdot 677$ & $\begin{array}{l}0 \cdot 22 \\
* * *\end{array}$ \\
\hline
\end{tabular}


the change in frequency with age in these postures $(\mathrm{r}=-0.228$ to $-0.493, \mathrm{p}<0.05,0.01$ or 0.001$)$. However, dominant hand work tremor frequency declined significantly with age $(r=-0 \cdot 209, p<$ $0 \cdot 05$ ).

In adults tremor amplitude did not change with age. But the decline in the frequency of work tremor in children continued into adulthood in both hands $(\mathrm{r}=-0.370$ and $-0.397, \mathrm{p}<0.001)$.

\section{Inftuence of height and weight}

Since height and weight vary with age particularly in children, multiple linear regression analysis was carried out for tremor amplitude and for frequency to evaluate whether changes in stature provided a better explanation than age of changes in tremor parameters. To determine whether height and weight provided any further explanation of amplitude and frequency variance, age was added first and then height and weight in a step-wise manner. The stepwise addition of height or weight to the regression of tremor amplitude on age did not increase $\mathbf{R}^{2}$ significantly in any posture in children. In adults age did not significantly account for any multiple variance. However, the addition of weight significantly increased $R^{2}$ from 0.027 to $0.113(p<0.05)$ for rest tremor in the non-dominant hand, and height significantly increased $R^{2}$ in postural tremor from 0.001 to 0.166 (non-dominant hand $p<0.01$ ) and from 0.011 to 0.096 (dominant hand $p<0.05$ ) suggesting that height and weight were superior to age in predicting rest and postural tremor amplitude in adults. This was confirmed when the multiple linear regression analysis was repeated by selecting the variable that accounted for the greatest fraction of the variance in amplitude or frequency and then in turn, those accounting for the greatest fraction of the residual variance. The resulting coefficients are shown in table 3 along with the multiple correlation coefficient $\mathbf{R}^{2}$. A significant amount of the variance of tremor amplitude in adults for rest and postural tremor could be explained when height and weight were considered with age (table 3 ) whereas the correlation coefficient for simple linear regression of amplitude on age for this group had not been significant (table 2).

$\mathbf{R}^{2}$ was always higher for rest and postural tremor amplitude than for work tremor amplitude in children and in adults (table 3 ).

Age, height and weight accounted for up to $28 \%$ of the variance in rest and postural tremor frequency particularly in the non-dominant hand in children ( $p$ $<0.001)$ but less in adults $(5-8 \%)$. On the other hand the variance in work tremor frequency was more dependant on age (see table 2 ) in adults ( $p$ $<0.001$ dominant hand) and the addition of weight significantly raised $R^{2}$ from $0 \cdot 15$ to $0 \cdot 22$ in the nondominant hand and from $0 \cdot 16$ to 0.23 in the dominant hand $(p<0.05)$.

\section{Discussion}

Tremor is the result of mechanical and neuromuscular factors with some minor cardiovascular influence. Stiles ${ }^{8}$ has commented on the negative relation between dominant frequency and amplitude of tremor and has suggested that this is characteristic of a viscoelastic-mass mechanism, though he maintained that a neural feedback reflex component would probably be present at oscillations above $100 \mu \mathrm{m}$ in amplitude. A negative frequencyamplitude relation is clearly present in postural and possibly rest tremor since the highest amplitudes are usually associated with the lowest frequencies. A partly mechanical explanation is acceptable for postural tremor particularly when the arm is unsupported and most susceptible to mechanical contributions. Multiple linear regression analysis provided further evidence for mechanical influences in children, in whom height and weight increase with age. Age, height or weight could equally predict change in tremor amplitude or frequency. In adults in whom height and weight do not show a simple correlation with age, the addition of height (for rest tremor) and weight (for postural tremor) for the regression of tremor amplitude on age significantly increased the multiple correlation coefficient. According to Stiles, ${ }^{8}$ when the oscillations reach a greater amplitude than around $100 \mu \mathrm{m}$ then reflex feedback may occur and the oscillations arising from loop delay would superimpose on those already occurring. Such a mechanism may occur in postural tremor, where mechanical oscillations tend to be higher and reflex feedback may then arise.

There are other factors which should be considered when comparing tremor in adults and children. Firstly, the effect of the weight of the accelerometer on the hand of a child compared with that of an adult and secondly, a related factor, the effect of fatiguing in children. The accelerometerperspex ring mass of $15 \mathrm{~g}$ can be estimated to be about $3 \%$ of the mass of an adult hand and about $8 \%$ of the mass of the hand of a 8-year-old child. The effect of this higher ratio of accelerometer-tohand weight on the spectrum could be shown by increasing the ratio of accelerometer-to-hand mass in adults. When in one adult subject, the relative mass of the accelerometer was increased from $3 \%$ to $8 \%$, there was no effect on the dominant frequency of the spectrum for rest, postural or work tremor of either hand. In rest tremor, the amplitude of the spectrum was lower when the extra mass had been 
added but the major change occurred in the 15-20 $\mathrm{Hz}$ band. There was very little change in the postural tremor spectrum at any frequency. While maintaining an upward force of 1 Newton, the added mass had the effect of increasing work tremor amplitude, the major change was between 25 and $50 \mathrm{~Hz}$. These results suggested that the higher amplitude seen in children during work tremor could be the result of the weight of the accelerometer relative to the hand. The differences between children and adults in rest and postural positions cannot be explained simply by this factor, nor do the changes in frequency appear to be dependant on this ratio since they were in frequency bands higher than those in which age differences were found.

The possibility of a greater amount of fatigue being experienced by children, was estimated by comparing the beginning and end of recordings. For five of the subjects in each of the nine age groups the overall rms acceleration in 5 second samples over the one minute of recording were obtained. A comparison using a paired $t$ test between the acceleration in the first 5 second sample with that in the last sample revealed no statistically significant differences in any age group. Thus it appeared that at the end of one minute, fatigue had not caused a greater amplitude of tremor at the end of the recording.

Frequency changes with age may be a result of changing delays in the servoloop with age. Up to the age of approximately 18 years, the length of the stretch reflex servoloop is increasing because of the increase in length of the arm during growth. It has been predicted that longer delays in the loop would lead to lower frequency oscillations ${ }^{y}$ which is the change that was seen with increase in age. However it has been shown that in proximal arm muscles loop delay is of the order of $30 \mathrm{~ms}$ while that of the fingers is $50 \mathrm{~ms}$, these should (if tremor were due to the stretch reflex alone) create oscillations of $17 \mathrm{~Hz}$ and $10 \mathrm{~Hz}$ respectively. ${ }^{10}$ The change in conduction velocity with age $\left(8-9 \mathrm{~ms}^{-1}\right.$ between 30 and 80 years" predicts a shift in frequency of only $1 \mathrm{~Hz}$ which is insufficient for the changes reported here. Marshall ${ }^{2-3}$ and Marsden et al ${ }^{5}$ have rehearsed the argument for changes in synaptic delay or in conduction velocity not being sufficient solely to account for changes in tremor with age.

Tyron ${ }^{12}$ described developmental equations for postural tremor using the original data published by Marshall. ${ }^{2} \mathrm{He}$ suggested that the change in right hand postural tremor frequency $(\mathrm{Y})$ with age $(\mathrm{X})$ could be described by the equation:-

$$
\mathrm{Y}=0.2901 \mathrm{X}+4.0593
$$

The corresponding equation for our data (assuming the right hand is usually dominant) is:-

$$
\mathrm{Y}=0 \cdot 089 \mathrm{X}+6.84
$$

For the non-dominant hand the equation is very similar to that fitting Marshalls' data:-

$$
\mathrm{Y}=0.285 \mathrm{X}+3.747
$$

We can now construct equations to describe change in tremor frequency and amplitude in other postures in children and adults and take into account the influence of height and the weight of subjects using the coefficients in table 3 and 4 . Hence a more accurate description for the change in non-dominant hand tremor frequency with age in children could be:-

$$
\mathrm{Y}=(0.322 \times \text { age })-(2.197 \times \text { height })+(0.022 \times
$$

The results in this investigation of the variation of tremor with age, would seem to explain the discrepancy between the results of Marshall ${ }^{2-3}$ and Marsden el al.5 Marshall's measurements were most comparable with the postural tremor test used in this study in which it was also found that children showed a lower dominant frequency of tremor; so too did adults in later life. Marsden et al $\mathrm{s}^{5}$ measurements were more comparable in position of measurement with the work tremor test in this study in which it was found that children did not show a lower frequency than adults but frequency was lower in the oldest group of adults studied. Hence the nature of the variation of tremor with age depends on the posture adopted for the measurement. Marsden et al ${ }^{5}$ suggested that the lower frequency observations made by Marshall ${ }^{2-3}$ may have been due to his favouring low frequency components during visual analysis, particularly when no obvious peak was present in physiological tremor frequency bands. In this study, a peak was always present in children and Marshall's low frequency result was confirmed.

We record our thanks to all the subjects who agreed to have their tremor measured; special thanks are due to Mr P Chambers and to Mr J Gregory through whom arrangements were made to make measurements in children. We are grateful to Dr JM Patrick for guidance with the statistical analyses.

\section{References}

' Marshall J, Walsh EG. Physiological tremor. J Neurol Neurosurg Psychiatry 1956;19:260-7.

${ }^{2}$ Marshall J. Physiological tremor in children. J Neurol Neurosurg Psychiatry 1959;22:33-5.

${ }^{3}$ Marshall $\mathbf{J}$. The effect of ageing upon physiological tremor.J Neurol Neurosurg Psychiatry 1961;24:14-7.

${ }^{4}$ Buskirk C, Fink RA. Physiological tremor an experimental study. Neurology (Minneap) 1962;12:361-70. 
${ }^{5}$ Marsden CD. Meadows JC, Lange GW, Watson RS. Variation in human physiological finger tremor with particular reference to changes with age. Electroencephalogr Clin Neurophysiol 1969;27:169-78.

- Gatev V, Ivanov I. Studies on postural tremor in normal children. Dokl Akad Nauk SSSR 1969;22:587-90.

${ }^{7}$ Birmingham AT, Williams EJ, Wilson CG, Wright P. Finger tremor in normal subjects. $J$ Physiol (Lond) 1977;276:20-21P.

"Stiles NA. Frequency and amplitude relations for normal hand tremor.J Appl Physiol 1976;40:44-54.

${ }^{4}$ Stein RB, Oguztorelli MN. Tremor and other oscilla- tions in neuromuscular systems. Biolog Cybern 1976;22:147-57.

${ }^{10}$ Marsden CD. The mechanisms of physiological tremor and their significance for pathological tremors. In: Desmedt JE, ed. Physiological Tremor, Pathological Tremor and Clonus. Progress in clinical neurophysiology Vol. 5 Basel Karger, 1978.

"Norris AH, Shock NW, Wagman IH. Age changes in the maximum conduction velocity of motor fibres in human ulnar nerves. J Appl Physiol 1953;5:589-93.

12 Tyron WW. Developmental equations for postural tremor. Science 1982;215:300-1. 